\title{
LUZ, SÍMBOLO Y REVELACIONES A TRAVÉS DEL PAPIRO DE JEREMIIAS Y LA PRESENCIA DE LA VIRGEN MARÍA EN LA CATEDRAL DE SAN JOSÉ DE CÚCUTA
}

\section{LIGHT, SYMBOL AND REVELATIONS THROUGH JEREMIAH'S PAPYRUS AND THE PRESENCE OF THE VIRGIN MARY IN THE CATHEDRAL OF SAN JOSÉ IN CÚCUTA}

Mawency Vergel Ortega'

\section{Yannette Díaz Umaña²}

\section{Julio Alfredo Delgado Rojas ${ }^{3}$}

Universidad Francisco de Paula Santander

\section{RESUMEN}

El artículo tiene como objetivo analizar el fenómeno lumínico presente en la Catedral San José de Cúcuta en horario de 16 horas a 16:45

$1 \quad$ Filiación: Universidad Francisco de Paula Santander, Cúcuta, Colombia. Postdoctorado en ciencias sociales, niñez y juventud. Doctor en Educación. Directora Maestría en Educación Matemática. mawencyvergel@ufps. edu.co | https://orcid.org/0000-0001-8285-2968

2 Filiación: Universidad Francisco de Paula Santander, Cúcuta, Colombia. Magister en Gestión Urbana. Directora departamento de Arquitectura y Urbanismo. yannettedu@ufps.edu.co | https://orcid.org/0000-0003-4582-1593 3 Filiación: Universidad Francisco de Paula Santander, Cúcuta, Colombia. Magister en Educación Matemática. julioalfredo@ufps.edu.co | https://orcid.org/0000-00016944-832X horas desde los imaginarios colectivos de la comunidad católica que habita San José de Cúcuta y desde la incidencia lumínica, ubicación de la catedral y radiación solar. La investigación sigue un enfoque cualitativo desde el análisis de contenido, apoyado en análisis cuantitativo y uso de instrumentos como la entrevista y herramientas de simulación. Resultados muestran categorías emergentes asociados a la fe, como la imagen de la virgen María, Jesús redentor, juan el discípulo, resurrección, asunción, ángeles, alma inmaculada, y frente a explicaciones desde la física y elementos como 
reflectores, luz incidente; se concluye que se constituye el vitral "Jeremías", en un elemento de la envolvente arquitectónica en la cara oeste que se vincula con los efectos lumínicos internos en la zona del presbítero, y ubica de forma estratégica entre el sol y el fenómeno captado, cuya iluminancia podrá surgir del fenómeno de la luz a través solo, de los cristales de forma excepcionalmente blanca como escasas figuras de las columnas, capiteles y el papiro de dicho vitral, sin embargo, la forma de la figura con aspecto humano no corresponde al diseño del cristal con el que se perfila, donde significados, creencias y, la coherencia entre la fidelidad de la representación, vida de María y de Cristo, asociadas a necesidades y creencias de los fieles y su entorno, conmueve, perdura en el imaginario colectivo como símbolo y señal de salvación.

\section{ABSTRACT}

The article aims to analyze the light phenomenon present in the Cathedral of San Jose de Cucuta from 16 hours to $16: 45$ hours from the collective imagination of the Catholic community living in San Jose de Cucuta and from the incidence of light, location of the cathedral and solar radiation. The research follows a qualitative approach from the analysis of content, supported by quantitative analysis and the use of instruments such as the interview and simulation tools. Results show emerging categories associated with faith, such as the image of the Virgin Mary, Jesus the Redeemer, John the Disciple, Resurrection, Assumption, Angels, Immaculate Soul, and facing explanations from physics and elements such as reflectors, incident light; it is concluded that the stained glass window "Jeremiah" is constituted, in an element of the architectonic surrounding in the west face that is related with the internal luminous effects in the zone of the presbyter, and it is located of strategic form between the sun and the captured phenomenon, whose illuminance will be able to arise from the phenomenon of the light through alone, of the crystals of exceptionally white form like scarce figures of the columns, capitals and the papyrus of this stained glass, however, the shape of the figure with human aspect does not correspond to the design of the crystal with which it is outlined, where meanings, beliefs and, the coherence between the fidelity of the representation, life of Mary and Christ, associated to needs and beliefs of the faithful and their environment, moves, lasts in the collective imaginary as a symbol and sign of salvation.

\section{INTRODUCCIÓN}

La religiosidad popular católica se sostiene en un culto, que expresa creencia y que contiene elementos fundamentales de una cultura. En Homero, aparece con frecuencia la palabra luz asociada al resplandor, procedente de fuente celeste (Mungler, 1964), luz de los ojos, “la existencia”, considerada salud, salvación, felicidad y victoria (Bailly, 2000). La luz aparece en los diez principios antitéticos de Pitágoras (Moulton, 1980). Platón asocia el bien y el mal a la luz del sol y la oscuridad y surge la palabra $\varphi \square \varsigma$ revalorizando e iluminando y salvando, puesto que griegos relacionaban con la imagen de las tinieblas la idea de culpa y con la luz la idea de salvación y redención del mal (Kittel, 1988). Aristóteles en su estudio a Platón y la mística de los números fue objetado con el descubrir de cantidades irracionales, donde luz y oscuridad forman parte de una realidad sensible.

En diferentes escenarios de las iglesias se visualizan fenómenos con explicación científica que generan diferentes percepciones e imaginarios en la comunidad. Uno de estos fenómenos lumínicos aconteció el 13 de agosto a las $16: 30 \mathrm{pm}$ de la tarde en el 2020 en la catedral San José de Cúcuta- Colombia, a la cual diferentes feligreses expresaron su asombre frente a óptica como geometría de la luz y la fe en los creyentes; es importante ante estos fenómenos, realizar un análisis lumínico 
a la arquitectura de la catedral. Antes que nada, evaluar la posibilidad de atribuir el fenómeno de iluminancia que se observó a la derecha de los pies de la cruz, a los efectos lumínicos de luz artificial, todo ello dado a las cualidades del rendimiento y focalización lumínica que generan las luces Led para interiores. La aparición, como un efecto especial, está acompañada de manifestaciones visuales propias de la imagen (Gruzinski, 1995: 140), Se desarrolla de esta manera la colonización de lo imaginario como un proceso de colonización simbólico del imaginario. El artículo busca explicar estos fenómenos desde imaginarios, y desde la incidencia de la luz solar.

\section{METODOLOGIA}

La metodología empleada es de carácter cualitativa (Largo, Rojas, Vergel, 2020), apoyado en estudios de Gilbert Duran se toma el imaginario (Castoriadis, 2007), como categoría simbólica que "representa el conjunto de imágenes mentales y visuales, organizadas por la narración, por la cual un individuo y una sociedad, organiza y expresa simbólicamente sus valores existenciales y su interpretación del mundo frente a los desafíos impuestos por el tiempo y la muerte" (Durand, 2000: 10). se aplica el análisis de contenido, documental, sociológico de discurso para analizar mediatización de la comunidad creyente de San José de Cúcuta, así mismo se analiza desde el ámbito cuantitativo análisis técnico de trayectorias de la luz y análisis de fenómeno óptico. Instrumentos incluyen entrevista virtual abierta de dos preguntas. Informantes clave lo constituyen sacerdotes y 150 feligreses de la comunidad asistente a eucaristía de día 13 del mes de agosto del año 2020.

El estudio cuenta con tres fases, la primera asociada a representaciones de la comunidad frente a fenómenos de luz visualizados en el altar de la catedral en eucaristías celebradas a las 16:00 horas a través de red social facebooklive. Una segunda fase contempla analizar explicaciones frente a categorías emergentes tales como análisis de posición de reflectores, análisis de iluminancia y finalmente la triangulación de resultados. Para el proceso de análisis de luz, se hace uso de metodologías gráficas de simulación solar, en este caso Autodesk Revit, software de diseño inteligente de modelado BIM para arquitectura, que facilita los estudios solares, el impacto de la luz natural y las sombras en las parte exterior e interiores de los proyectos.

\section{RESULTADOS}

\section{Símbolo y representación}

Categorías emergentes frente a diálogos con la comunidad que asistió a eucaristías a $4 \mathrm{pm}$ de manera virtual, fueron sagrado, presencia de la Virgen María, Manto sanador, Jesús Resucitado, alma de familiar fallecido, despedida, espíritu santo, asunción de la virgen. Categorías emergentes presentes en testimonios de sacerdotes fueron Virgen María, a la diestra de Dios, Juan discípulo amado, luz de vitral, presencia de Dios en el altar. El milagro representa el fenómeno de una imagen investida con la legitimidad que le otorga la divinidad que contiene para representar en el imaginario colectivo, en objeto de fe, culto y al ser en un acto público se declara su naturaleza como objeto sagrado. Dentro de la institucionalización del imaginario, es fundamental la definición de un lugar digno para su visita, asociada por los fieles como símbolo de pureza y adoración, de lugar sagrado, de sitio para orar y presentar peticiones por familiares relacionado al milagro de la sanación. Además de la mediación, entre imagen y Dios, se demanda la necesidad de que la imagen más allá de ser milagrosa representa paz para familiares y amigos de aquellos que han partido al "encuentro con Dios" (Informante 5). El recurso del milagro es elemento de las comunidades religiosas en la evangelización y en el movimiento de la fe de los católicos 
(Gruzinki, 1995: 114). La imagen de la Virgen María arrodillada a los pies de la cruz con la mirada dirigida a su hijo, y a la izquierda del sacerdote representando a Juan el discípulo amado, y su ascensión durante el transcurso de la eucaristía, señala el encuentro con Dios, la remembranza de aquel día en el cual Jesús es crucificado, el ascenso de la sombra evoca la asunción como expresión devocional; y la hora en la cual esta luz se apaga momentáneamente, es relacionada al eclipse que sucede, el volver de la luz relacionado con la resurrección o desde la mirada de otros fieles, tal como lo manifiestan temas tradicionales del arte fúnebre, asociado a creencias de inmortalidad del alma del fallecido. Una segunda imagen asociada por los fieles representa a Jesús como Cristo redentor, simboliza una relación de un nosotros, no difusa, mediada por una situación de salvación y protección ante necesidades y sufrimientos con la imagen de Dios. Una tercera mirada, desde las voces de familiares, relacionan sombras, luz y trayectoria de la luz, a ángeles que acompañan el alma del fallecido al encuentro con el Padre.

Estas expresiones figurativas de la comunidad cristiana católica creyente de San José de Cúcuta, muestran el interés en atribuir significado cristiano a imágenes, sombras ya conocidas o utilizadas en representaciones en otros escenarios, es decir el contenido de las sombras, posee significado religioso cristiano y las formas de representación no difieren de las difundida evocando los fundamentos de la propia fe a través de un lenguaje figurado que manifiesta el preservar la fe en el culto donde Dios se revela, Jesús y María son representables como testimonio visual de los fieles atribuyéndole estos un origen divino a la imagen proyectada allí "virgen arrodillada, rostro perfilado, ojos observando a su hijo, en señal de dolor y a su vez de adoración, lo que otorga vitalidad a un semblante austero, extrañamente inerte, silencioso y suplicante". La tradición literaria presenta a la virgen con su manto y un Jesús alto de cabellos ondulados a la altura de las orejas partido a la mitad como los nazarenos, con una túnica y sus brazos extendidos en señal de salvación e indicando los medios para alcanzarla. La religión católica cristiana se constituye en una religión de la memoria, donde fieles ven a Cristo como el origen y difusor $\mathrm{n}$ o solo de la palabra sino de su imagen, y este elemento influye de manera sociológica en el imaginario colectivo. En la creencia religiosa convergen la fe, la esperanza, el temor, la confianza en dicha fuerza que expresada en imagen incide desde la práctica de las costumbres religiosas, del rito, mediada por la palabra, la interpretación del sacerdote frente a la palabra de Dios y el contexto, la dadiva, la visita, la entrega y la transformación de la vida cotidiana del creyente. El imaginario religioso como fenómeno histórico social se transforma, cada una de las imágenes referenciadas da cuenta de una relación particular en un contexto y época de pandemia, de muerte, de aislamiento, la cual incide de manera significativa en la fe y práctica religiosa de la comunidad creyente, en la constitución de memoria y materialización de la identidad que como católicos le caracteriza. La imagen religiosa vista desde cierta perspectiva se constituye en un emblema de poder, punto de partida para dar cuenta de la representación colectiva en donde se articulan creencias, percepciones, imágenes, símbolos, íconos, ritos y acción. El imaginario religioso, inmerso en la representación social se origina a partir de relaciones que subyacen del colectivo con la memoria subjetiva, significaciones religiosas de la sociedad en la que habita y de la cual ha hecho parte activa

No obstante, otras miradas se dirigen a la realidad y buscan explicaciones en lo físico y elementos del escenario durante la eucarística, así se asocia la luz a la presencia de reflectores en el templo, a la creación de estas escenas, y a la luz que incide de los rayos del sol. Desde esta perspectiva se analiza e identifican en el sistema 
eléctrico del edificio, los reflectores parabólicos de LED, que son los más usados, pues ofrecen la posibilidad de dirigir la luz de modo más variado, obteniendo una buena difusión en interiores. Así la propiedad óptica más importante de este tipo de reflector da lugar a un haz de rayos reflejados en paralelo al eje parabólico, lo cual genera una buena difusión limitada de deslumbramiento (Assaf, Colombo y 0'Donell 2002: p.8), adicional a este efecto de dispersión, y los más de 8 metros sobre el nivel del suelo, de estas fuentes de luz en la catedral, respaldan la imposibilidad de generar un enfoque preciso de la luz, de allí resulta que prevalece los niveles de uniformidad lumínica artificial, por lo que no hay explicación de la iluminancia junto a la cruz.

Incidencia lumínica. Continuando con el análisis, luego de descartar la opción lumínica artificial como generador del fenómeno, el estudio se concentra en la incidencia lumínica natural en la catedral. De antemano la definición del sistema de iluminación natural, se basa en el conjunto de elementos que se utilizan en un espacio para iluminar con luz natural (Michalski 2009). La cantidad, calidad y distribución de la luz interior está asociada al funcionamiento de los sistemas de iluminación cenital, lateral o combinada, de la manera en que se encuentran ubicadas las ventanas y los colores de los espacios que inciden en una reflexión de la luz óptima. (Garrido, y Trujillo 2015 p: 13). Así la intensa luz blanca vista al lado del Cristo en el ábside denominada para efectos de este estudio, iluminancia que es la densidad del flujo luminoso que incide sobre una superficie (Garrido, y Trujillo 2015 p: 23), podría simplemente ser la respuesta lumínica del sol al penetrar al interior del recinto, a través de algún elemento de su envoltura como lo son vanos y vitrales. Dado que, en la lectura arquitectónica de la catedral, la iluminancia ocurrió en la zona presbiteral, justo debajo de la cúpula se concentrará el análisis en esta zona. Así, entre los cuerpos traslucidos, se visibilizan, el óculo, 8 vitrales del tambor y 8 vitrales del transepto susceptibles a proyectar al interior del recinto huellas lumínicas que podrían ser la respuesta a la iluminancia. De ahí se considera

“El nivel de radiación solar
directa que recibe la fachada de
unedificio depende delazimutde
la pared, es decir, la orientación
de la misma y de su inclinación.
Ésta además influye en otros
parámetros del diseño pasivo
de un edificio como el diseño
de los elementos de protección
solar o el comportamiento de
la envolvente" (Esquivias 2017 :
p.169)

Ahora, en el siguiente gráfico se puede determinar la radiación solar directa en las fachadas de la catedral, distinguiendo las superficies de mayor incidencia, por los colores amarillos y naranjas, que representan los rayos crepusculares. Por el contrario, los azules y verdes corresponden a las superficies menos desplegadas ante la exposición del sol justo en ese momento para el cual se realiza este análisis solar. En el examen gráfico se puede descartar el óculo de la cúpula, ya que el azimut no cobra en él, ninguna incidencia. (Figura 1) 


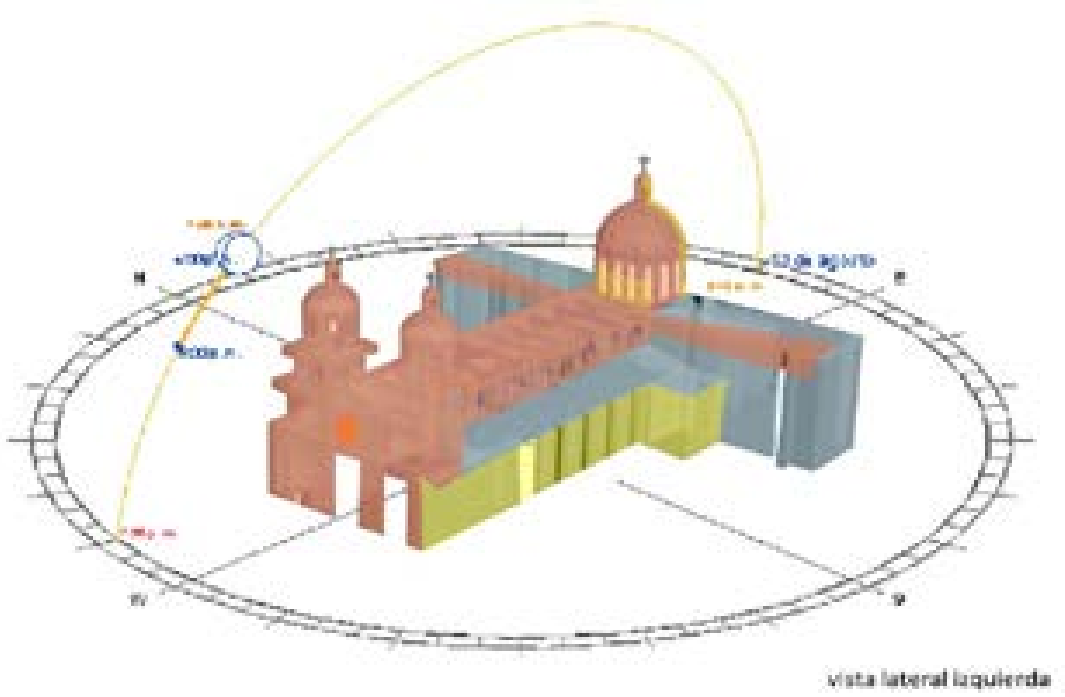

Figura 1. Vista lateral izquierda de la incidencia solar en la catedral de San José, el 13 de agosto a las 4:00 pm el 2020. Fuente: Modelado Autodesk Revit, por Catherine Contreras.

En particular se estima que el ángulo de orientación desde el norte real, conocido como azimut, corresponde a 285 grados, de tal manera que se privilegia la iluminación en sentido diagonal del noroeste al sur- este. En consecuencia, la fachada principal, y demás superficies que miran al oeste, como se expresa en el modelado, aparecen de color naranja a amarillas en respuesta a la intensa iluminación.

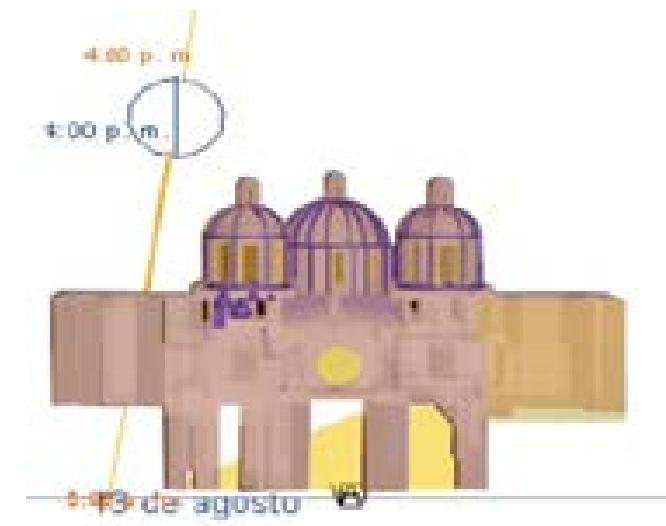

En contraposición la fachada posterior orientada al este, que en horas de la tarde se muestra en penumbra, representada así con los colores azules y verde característicos en el simulador. De esta revisión, se descartan 4 vitrales ubicados al este en el tambor, y los de transepto al este, por lo no se encuentran afectados lumínicamente

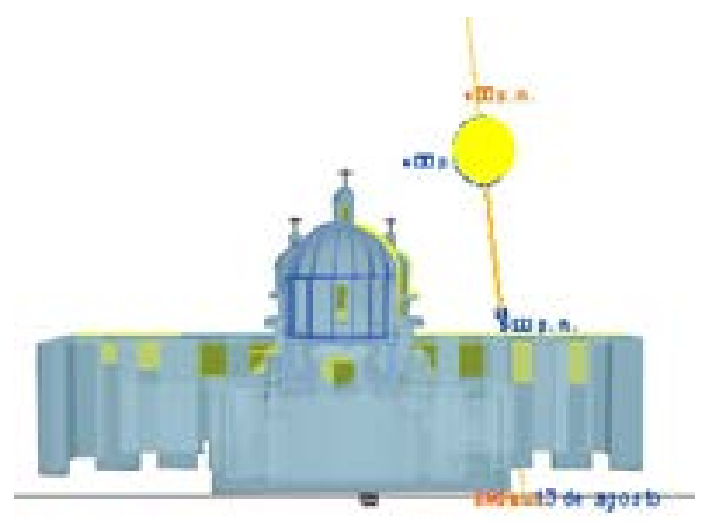

Figura 2. Vista fachada principal y fachada posterior de la incidencia solar en la catedral de San José, el 13 de agosto a las 4:00 pm el 2020. Fuente: Modelado Catherine Contreras. 
Por consiguiente, quedan claros que los elementos de la envolvente arquitectónica como son los 4 vitrales del tambor y los 4 vitrales en el transepto ambos en la cara oeste se vinculan con los efectos lumínicos internos en la zona del presbítero. No obstante, es necesario precisar la posición exacta del sol, para ver los posibles efectos de la focalización lumínica al interior de la catedral. En este cruce de variables la altitud del sol a $38.5^{\circ}$, lo que significa la distancia angular vertical que hay entre un cuerpo celeste y el horizonte y el azimut es el ángulo que forma el cuerpo celeste y el norte, medido en sentido de rotación de las agujas de un reloj alrededor del horizonte del observador, de allí el azimut es de $285^{\circ}$, esto permite presumir la dirección de los rayos crepusculares. Con estas precisiones se genera el plano arquitectónico, mostrando el ingreso de la luz por los vitrales del tambor proyectado en la pared del transepto y ábside en colores naranjas, pero a una altura mayor de $8 \mathrm{~m}$. Lo que, los descarta también como los causantes de la iluminancia. (Imagen 3)

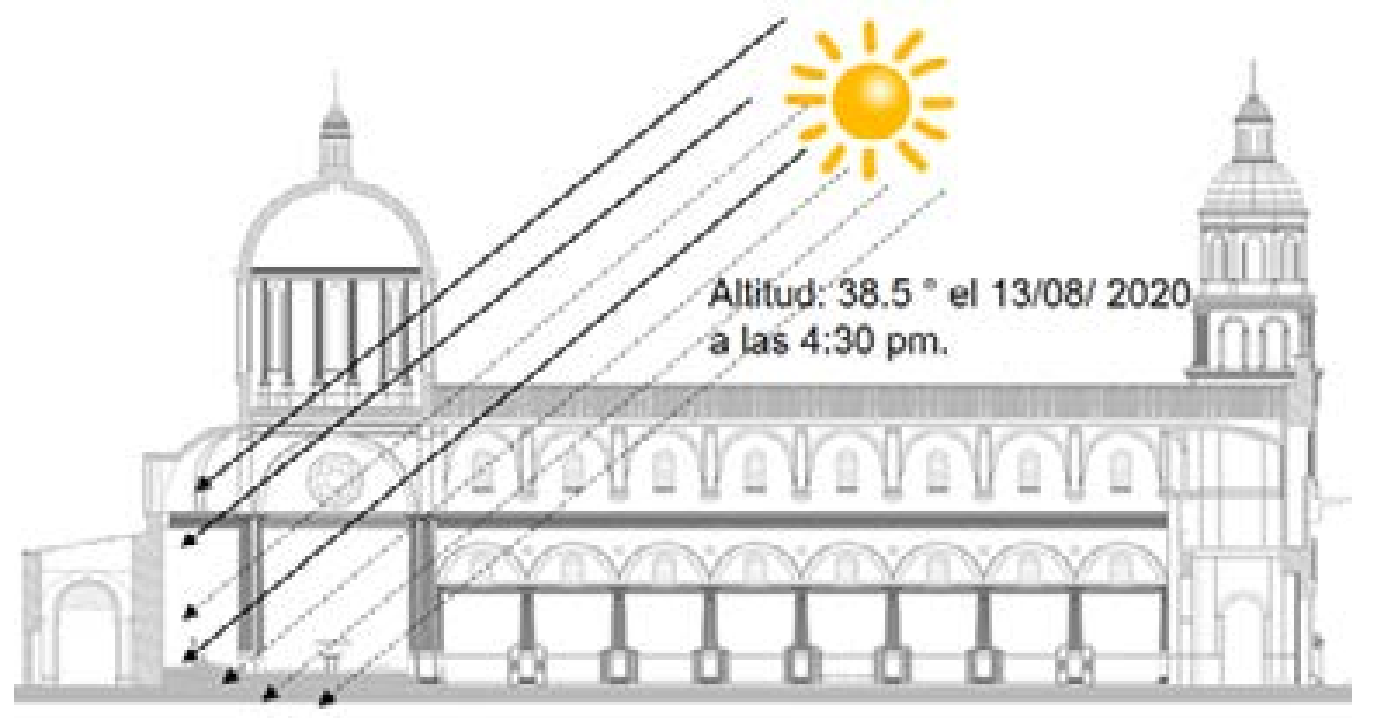

Figura 3. Corte arquitectónico con la incidencia solar. Fuente: Autores

Sin embargo, los vitrales del transepto vistos en la figura 3, presenta grandes posibilidades de ajustarse convenientemente a este fenómeno, pero solo la primera vidriera, se ajusta al ángulo de inclinación con acceso hasta el ábside. Dicho de otra forma, esta oportunidad lumínica al lugar de estudio, es muy limitada ya que el muro en su extremo norte del ábside sobresale impidiendo la incidencia del rayo a través de otras superficies laterales (Figura 4). En consecuencia, resta solo asegurar, sin lugar a dudas, que el vitral "Jeremías" se ubica de forma estratégica entre el sol y el fenómeno captado. La resplandecencia de colores tornasolados y naranjas proyectadas al interior del edificio, demuestra su composición cromática en colores oscuros azules, verdes, naranja y castaños. Por lo que la iluminancia podrá surgir del fenómeno de la luz a través solo, de los cristales de forma excepcionalmente blanca como las escasas figuras de las columnas, capiteles y el papiro de dicho vitral. 

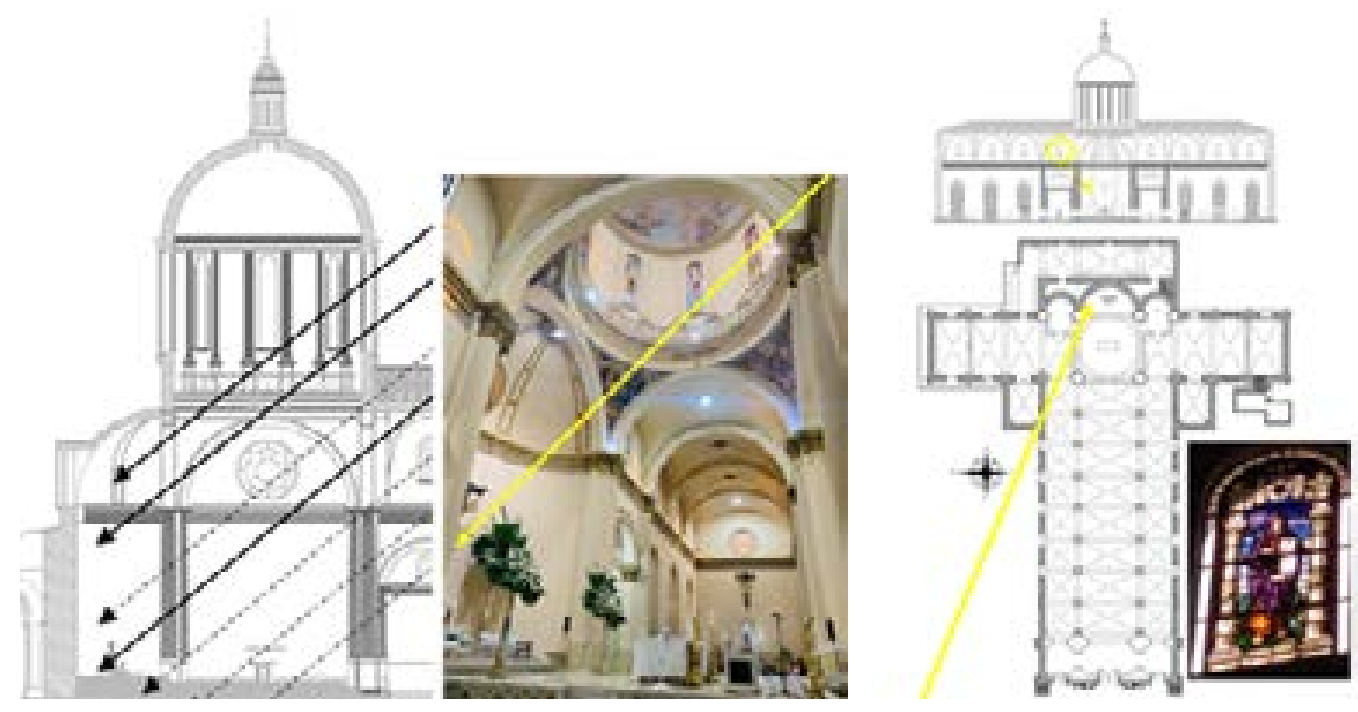

Figura 4. Planta y Corte arquitectónico con la incidencia solar desde el vitral de Jeremías hasta el ábside. Fuente: Elaboracion Propia.

Lo anterior quiere decir, que la posición del sol, justo en ese momento, podria eventualmente formar la iluminancia. Sin embargo, la forma de la figura con aspecto humano no corresponde al diseño del cristal con el que se perfila. En este sentido la iluminancia en los pies de la Cruz, podría responder a un fenómeno solar que es natural, y que en la distorción del papiro del vitral, por donde atravieza la luz, de manera transversal, se genere tal visión. Es probable que se cree a partir de esta condición, un efecto tipo lupa al deformar de cierta manera sus contornos para dar esa impresión del perfil de la Santísima Virgen María.

Triangulación Religión y ciencia presentes en un fenómeno no desconocido frente a las apariciones de la virgen en los últimos años. Las visiones en los casos de Medjugorie en la antigua Yugoslavia y Kibeho en Ruanda, todavía no ha obtenido ninguna forma de reconocimiento oficial (Novoa 2002, 365). De cierta manera, inclusive los acontecimientos milagrosos relatados en la Biblia tambien han sido motivo de incredulidad y sometidos a estudios para verificar la veracidad de los hechos. Vale la pena en este sentido citar la investigacion realizada por el Centro Nacional de Investigación Atmosférica
(NCAR) y la Universidad de Colorado en Boulder (CU), que buscan dar explicación, al fenómeno narrado en el Éxodo 14 en el Mar Rojo. De alli se logra probar mediante simuladores que un fuerte viento de 63 millas por hora podría haber hecho retroceder las aguas. La explicación se da bajo las leyes de la dinámica de fluidos. El investigador se refiere al viento como un milagro divino, por la intensidad dejando un paso de tierra seco con agua a ambos lados. De esta forma cuando los israelitas ya estaban en la otra orilla, las aguas volvieron a unirse (el viento se paró) y los soldados egipcios se ahogaron. El estudio confirma que la separación del agua pudo suceder con base a las leyes físicas, reconociendo lo incriblemente oportuno de la intensidad del viento y del momento (ABC CIENCIA 2014).

Este ambivalente mensaje entre la explicación cientifica del fenómeno y lo coincidencial, García (S.F.) lo declara como acciones bajo la total potestad de Dios, visto no solo en la separación del Mar Rojo, sino en multiples citas bíblicas. Por ejemplo, con las 10 plagas de egitpto, que responden sencillamente a causa naturales, determinadas por los fenómenos del clima, 
estaciones y geografía ${ }^{4}$, pero salidas de sus temporalidades usuales, lo que demuestra, su anomala conducta. De esta manera se afirma que al desatarsen estos fenómenos de acuerdo al tiempo justo, respondiendo a ciertas situaciones, como es el caso del clamor de Moises, constituye evidencia de la mano de Dios (García S.F).

A lo que quiere conducir estas circunspecciones, es precisamente ailustrar lo insolito o excepcional de la coincidencia solar y arquitectonica, con la celebracion Eucaristica de ese dia. En el caso de la catedral justo en ese momento a esa hora, dia, mes, con las miradas puestas en el altar, el clamor de los asistentes a traves de la virtualidad ante la pandemia y la aparicion de la iluminancia en forma de Virgen, facilmente reconocida, justo a los pies de la cruz, en plena celebracion eucaristica, elevandose lentamente hasta desaparecer, connota automaticamente simbologias para algunos o hechos enteramente demostrables. Para ltestimonio del audio J..."Responde a la tendencia contemporánea de no entender las manifestaciones de Dios. Nos cuesta entender los medios maravillosos de Dios, no dicernimos ante la presencia visible de la Santisima Virgen María a los pies de la cruz, a la derecha del sacerdote, es indiscutiblemente la Santisima Virgen Maria, es Maria , a la derecha del sacerdote".

Por otra parte Novoa, (2002) afirma que "Hay que evitar dos errores opuestos: el rechazo sistemático de la posibilidad de toda comunicación sobrenatural en la comunión de los santos, de forma sensible y la credulidad ingenua de reducir las apariciones a meros encuentros comunes y cotidianos"(p.365). De ahí se podria coincidir perfectamente con Garcia (s.f) y (ABC CIENCIA 2014), al dar por responsables los fenomenos naturales, sin descartar por lo inusual y coincidencial la potestad divina. De tal forma que la iluminancia menos observables en la región del norte de África. en forma de la Santisima Virgen Maria, puede tener su origen en los factores de iluminacion natural logrados con la ubicación exacta del sol con azimut de $285^{\circ}$ y una altitud de $38.5^{\circ}$ ese dia del 13 de agosto del 2020, a las 4:30 pm, a traves del papiro de Jeremias. Pero, sin lugar a dudas esta confluencia de tantos factores, resulta tan increible, que tampoco se podra descartar la autenticidad de la presencia visible de la Virgen Maria y la potestad de Dios sobre los factores de iluminacion natural que propiciaron la revelacion en la Catedral de San José de Cúcuta.

\section{CONCLUSIONES}

Emergen del fenómeno lumínico imágenes con características construidas como retrato colectivo desde formas tipológicas. Imágenes de la Santisima Virgen maría y Cristo redentor, asi como la representación simbólixa del sacerdote, proclaman en el imaginario de los creyentes la salvación y como alcanzarla.

El momento histórico vivido frente a un escenario de pandemia y aislamiento, refleja el comun sentir de los feligreces, y fortalece la fe de los cristianos católicos, emergiendo categorías asociadas a manifestaciones de Dios y al fenómeno lumínico con representaciones de la virgen inmaculada que asciende acompañada de ángeles serafines al cielo por voluntad de Dios, donde es el mesías quien traslada su madre al encuentro con Dios, asi mismo, se simboliza el poder otorgado al sacerdote como representación de Juan el discípulo amado a quien confía su madre; de otra parte, la pureza representada en la luz blanca resplandeciente que asiciende hasta la cúpula durante la celebración eucarística, donde la coherencia entre la fidelidad de la representación y vida de María y de Cristo, y las necesidades y creencias de los fieles y su entorno conmueve y perdura en el imaginario colectivo.

Se constituye el vitral "Jeremías", en un elemento de la envolvente arquitectónica en la cara oeste 
que se vincula con los efectos lumínicos internos en la zona del presbítero, y se ubica de forma estratégica entre el sol y el fenómeno captado, cuya iluminancia podrá surgir del fenómeno de la luz a través solo, de los cristales de forma excepcionalmente blanca como escasas figuras de las columnas, capiteles y el papiro de dicho vitral, sin embargo, la forma de la figura con aspecto humano no corresponde al diseño del cristal con el que se perfila.

Análisis de relatos y fuentes constituyen un modelo simbólico y doctrinal con poder de convicción retórica para inspirar el imaginario colectivo de la comunidad católica de San José de Cúcuta frente a su fe y la asunción de la virgen al cielo.

\section{REFERENCIAS.}

ABCCIENCIA (2014). ¿Pudo Moisés separar las aguas del Mar Rojo? Una explicación científica. Tomado de. https:// www.abc.es/ciencia/20141210/abci-pudomoises-separar-aguas-201412101242. html ?ref=https:\%2F\%2Fwww.google. com\%2F\#ancla_comentarios

Assaf, L, Colombo, E., O’Donell , B.(2002). Luminarias para iluminación de interiores. Bueno Aires; 1 - 45

Bailly, A. (2000). Dictionaire grec-francais. Paris:FC.

Castoriadis, C. (2007). La institución imaginaria de la sociedad. Buenos Aires: Tusquets

Durand, G. (2000). Lo imaginario. Barcelona: Ediciones del Bronce

Esquivias, M. (2017). Iluminación Natural diseñada a través de la Arquitectura. Análisis lumínico y térmico en base climática de estrategias arquitectónicas de iluminación natural. Tesis de Doctorado. Universidad de Sevilla, escuela técnica superior de arquitectura. Departamento de construcciones arquitectónicas. Área de instalaciones. https:// pdfs.semanticscholar.org/3c79/d282b17480a72 db94673bacb71abf16f845a.pdf

Garcia, E. (S.F). Curso Bíblico, El libro del Éxodo. Nazaret. Tomado de https://www.nazaret.tv/ inicio

Garrido, A y Trujillo, Y. (2015). Estudio de iluminación de los puestos de trabajo administrativos de la empresa comercializadora internacional verde azul S.A.S. Universidad Distrital Francisco José De Caldas, Especialización en Higiene, Seguridad y Salud en el Trabajo Bogotá D.C. http://repository. udistrital.edu.co/bitstream/11349/2907/1/ GarridoLopezAndreaCatalina2016.pdf

Gruzinski, S. (1995). La Guerra de las imágenes. México: FCE

Kittel, G. (1992) grande lessico del Nuovo Testamento Vol 16. Brescia.

Largo, F., Rojas, J., Vergel M. (2020). La Empatía en el aprendizaje de los estudiantes de educaión básica desde la perspectiva de la interacción social. Bogotá: Ecoe Ediciones

Michalski, S. (2009). Luz visible, radiación Ultravioleta e Infrarroja. Canadian Conservation Institute. Canada. Visto en http://www.cncr.gob. cl/611/articles-56474_recurso_8.pdf

Moulton W.F. (1980) A concordance to the Greek Testament. Edimburgo.

Mungler, CH. (1960) La lumiere et al visión dans la poesie grecquer. Revue des Estudes Grecques 73 40-72

Novoa, Carlos. (2002) ¿son verdad la apariciones? Theologica Xaveriana 135. 353-368 visto en : file:///C:/Users/ufps/ Downloads/21008-Texto\%20del\%20art\%C3\%AD culo-80310-1-10-20180124\%20(1).pdf 